\title{
Cardiovascular and alcohol-related deaths in abnormal glucose tolerant and diabetic subjects
}

\author{
B. Balkau ${ }^{1}$,E. Eschwège ${ }^{1}$, A. Fontbonne ${ }^{1}$, J.-R. Claude ${ }^{2}$ and J.-M. Warnet ${ }^{2}$ \\ ${ }^{1}$ Clinical and Epidemiological Research Unit, INSERM U21, Villejuif, \\ ${ }^{2}$ Laboratoire de la Direction de l'Action Sociale, de l'Enfance et de la Santé, Paris, France
}

\begin{abstract}
Summary. The aim of this study was to compare the causes of death and parameters related to alcohol consumption, between subjects diagnosed as diabetic, clinically by their general practitioner, or glucose intolerant and in particular as diabetic, using the epidemiological criteria of an abnormal glucose level following an oral glucose tolerance test. The subjects in this study were 7035 working men, aged between 44 and 55 years, who attended the first follow-up examination of the Paris Prospective Study, between 1968 and 1973. They were classified as 'clinically diagnosed diabetic' or, following an oral glucose tolerance test and the World Health Organisation criteria, as having 'oral glucose tolerance test diagnosed diabetes', impaired glucose tolerance or normoglycaemia. The relative risk of death by cirrhosis, in comparison with the normoglycaemic group, was 21 (95\% confidence interval: 9.1-49) in the group diagnosed diabetic by the oral glucose tolerance test, significantly different
\end{abstract}

$(p<0.02)$ from the group diagnosed diabetic clinically 3.1 (0.41-24); factors indicative of excessive alcohol consumption at baseline differed accordingly. In contrast, the relative risks for death by coronary heart disease were similar, 2.1 (1.0-4.1) and 2.7 (1.4-5.4) respectively; all of the factors defining the insulin resistance 'Syndrome X' (hyperglycaemia, hyperinsulinaemia, hypertension, hyperlipidaemia and also central obesity) and predictive of coronary heart disease were elevated in both groups of diabetic subjects. 'Diabetes', as diagnosed by the oral glucose tolerance test, might be the consequence of excessive alcohol consumption which could lead to insulin resistance, then to coronary heart disease, as well as to alcohol-related diseases.

Key words: Alcohol drinking, cardiovascular diseases, cirrhosis, Type 2 (non-insulin-dependent) diabetes mellitus, glucose tolerance test, insulin resistance, mortality.
Savage, in his 1722 publication: 'Nosologie méthodique ou distribution des maladies en classes, en genres et en espèces, suivant la méthode des Botanistes' listed seven forms of diabetes. The fifth was 'diabète du vin causé par l'abus du vin' [1]. A number of recent studies [2-5], as well as others over the last 20 years [6-9], have suggested that alcohol is associated with impaired glycoregulation.

The most convincing evidence of the association between alcohol and diabetes comes from the prospective study of Holbrook et al. [10]; alcohol was found to be a risk factor for the later development of diabetes in men. Further evidence comes from the cohort of middle-aged working men in the Paris Prospective Study [11]. The relative risks for cirrhosis and alcohol-related deaths in diabetic and impaired glucose tolerant subjects were very elevated: 13 (95\% confidence interval: 5.4 to 31 ) and 7.0 (3.1 to 16), respectively, in comparison to normoglycaemic subjects. Diabetes was defined in these two studies either by a physician's diagnosis or at screening, using the fasting and 2-h glucose concentrations following an oral glucose tolerance test (OGTT), and the WHO criteria [12].
In Type 2 (non-insulin-dependent) diabetic patients, the withdrawal of alcohol for less than one week has been shown to reduce hyperglycaemia to the level of non-alcohol consuming diabetic patients [13]. This casts some doubt on the diagnosis of diabetes by the OGTT in the alcohol consuming subject and on the grouping of 'known' and 'new' diabetic subjects in epidemiological studies.

The Paris Prospective Study population provides the opportunity, in a country where the consumption of alcohol is one of the highest in the world, (17.3 litres per person per year in 1977 [14]), to look at biological and clinical characteristics and causes of death of subjects, according to their glucose tolerance after an OGTT or their prior diagnosis as diabetic by their general practitioner.

\section{Subjects and methods}

The Paris Prospective Study is a study of cardiovascular risk factors in a population of 44 to 55 -year-old working men, who underwent up to five annual examinations over the period 1968 to 1978 . The general aims, detailed methodology and characteristics of this popu- 
Table 1. Classification of causes of death, International Classification of Diseases, revision 8 (ICD-8)

\begin{tabular}{lll}
\hline Cause & ICD-8 code & Description \\
\hline Cirrhosis & 571 & Cirrhosis of liver \\
Alcohol-related & \\
$140-149$ & $\begin{array}{l}\text { Malignant neoplasm of buccal cavity } \\
\text { and pharynx }\end{array}$ \\
150 & Malignant neoplasm of oesophagus \\
155.0 & Malignant neoplasm of liver \\
161 & Malignant neoplasm of larynx \\
291 & Alcoholic psychosis \\
303 & Alcoholism \\
Coronary heart disease & \\
$410-414$ & Ischaemic heart disease \\
427.0 & Congestive heart failure \\
427.1 & Left ventricular failure \\
519.1 & Acute oedema of lung \\
782 & Symptoms referable to cardiovascular \\
& and lymphatic system \\
795 & Sudden death (cause unknown) \\
& \\
Cardio-cerebrovascular disease & Ischaemic heart disease \\
$410-414$ & Other forms of heart disease \\
$420-429$ & Cerebrovascular disease \\
$430-438$ & Acute oedema of lung \\
519.1 & Symptoms referable to cardiovascular \\
782 & and lymphatic system \\
795 & Sudden death (cause unknown) \\
\hline
\end{tabular}

lation have been described elsewhere [15]. There were 7176 men who attended the first follow-up examination and had measures of the glucose concentrations at fasting and 2-h after a $75 \mathrm{~g}$ OGTT or who had already been diagnosed as diabetic.

The International Classification of Diseases, eight revision (ICD-8), was used to classify the causes of death, after 12-18 years of follow-up (an average of 15.6 years). Two groupings of causes of death related to excessive alcohol consumption were defined: cirrhosis and 'alcohol-related' deaths (Table 1). The codes defining two diseases of the circulatory system, coronary heart disease (CHD) and cardio-cerebrovascular disease are also shown in Table 1.

In France, the cause of death registered on the death certificates is confidential, thus causes were classified by an independent panel of physicians, using medical records and information from the family of the deceased. The cause of death was not established for 141 men. The 7035 men who were alive at the beginning of 1987 or with known cause of death are studied here.

The subjects diagnosed as diabetic before the study, the 'clinically diagnosed diabetic' patients, had been or were being treated by oral hypoglycaemic agents. Only eight of these men were treated by insulin, four of them irregularly. All had been diagnosed as diabetic after the age of 27 , were assumed to be Type 2 diabetic patients and were included in this analysis.

All other subjects were classified, using the fasting (G0) and 2-h (G2) glucose concentrations and the WHO 1985 criteria [12] following a $75 \mathrm{~g}$ OGTT as:
'OGTT diagnosed diabetic'
$\mathrm{G} 0 \geq 7.8 \mathrm{mmol} / 1$ and $/$ or $\mathrm{G} 2 \geq 11.1 \mathrm{mmol} / \mathrm{l}$
impaired glucose tolerant $(\mathrm{IGT}) \mathrm{G} 0<7.8 \mathrm{mmol} / \mathrm{l}$ and $7.8 \mathrm{mmol} / \mathrm{s} \leq \mathrm{G} 2<11.1 \mathrm{mmol} / 1$ non-diabetic/non-IGT $\mathrm{G} 0<7.8 \mathrm{mmol} / 1$ and $\mathrm{G} 2<7.8 \mathrm{mmol} / \mathrm{l}$.

There was no direct inquiry as to the alcohol consumption habits of all subjects, however, there were two surrogate measures: the mean corpuscular volume (MCV), a parameter correlated with alcohol consumption [16] and the diagnosis of definite 'cirrhosis' by the examining physician (which may have included fatty liver since it was based, in part, on hepatomegaly).

Subjects in this study answered a questionnaire which included questions on smoking habits. The clinical examination permitted the assessment of obesity by the body mass index (weight (kg) divided by height $(\mathrm{cm})$ squared) and of central obesity (ratio of iliac and thigh circumferences $[17,18]$ ). Blood pressure was measured with the subject in a seated position. Blood samples were taken at fasting and 2-h after a $75 \mathrm{~g}$ oral glucose load (the OGTT); analyses involved - cholesterol [19], triglycerides [20], glucose [21], non-esterified fatty acids [22] and insulin [23].

\section{Statistical analysis}

Quantitative characteristics were compared between groups using the Kruskal Wallis test and qualitative characteristics by a chi-square test. The analysis used the Spearman correlation coefficient, nonparametric confidence intervals for medians [24] and the trend test for proportions over 2-h glucose concentration classes [25]. Relative risks were estimated, after adjustment for age, using the Cox model [26]. The proportional hazards assumptions for this model were verified.

\section{Results}

Biological and clinical characteristics of the subjects, grouped according to their glucose tolerance and diabetic status, are shown in Table 2 . In comparing, at baseline, the subjects with 'OGTT diagnosed diabetes' to those with 'clinically diagnosed diabetes', statistically significant differences $(p<0.05)$ were observed for smoking, 'cirrhosis', central obesity, systolic blood pressure, 2-h plasma glucose, fasting non-esterified fatty acids and 2 -h insulin concentrations and the MCV. All differences were in the same direction, namely the 'OGTT diagnosed diabetes' group had values more elevated than the 'clinically diagnosed diabetes' group.

All parameters, except the 2-h insulin concentration and smoking, showed an increase in median value with increasing glucose intolerance over the three glucose tolerance categories defined on the basis of the OGTT: the IGT group had a significantly higher median 2 -h insulin concentration than those with 'OGTT diagnosed diabetes' $(p<0.01)$ (Table 2). All variables, except age, differed significantly $(p<0.05)$ between the three glucose tolerance groups.

In particular, the two parameters associated with alcohol consumption: 'cirrhosis' and MCV suggested excessive alcohol consumption in the 'OGTT diagnosed diabetes' group. There was a positive association between the percentage with 'cirrhosis' and the 2-h glucose concentration (Fig.1); the trend was statistically significant $(p<0.005)$ with the percentage for the "clinically diagnosed diabetes' group towards the middle of the range. Figure 2 shows that the median MCV also increased with the 2-h glucose concentration, $(r=0.8)$; an abrupt increase was seen at $11 \mathrm{mmol} / 1$, the cut-off point for 'OGTT diagnosed diabetes'. The median MCV for the 'clinically diagnosed diabetes' group was lower than that for any 2 -h glucose concentration class.

As shown in Table 3, compared to the non-diabetic/nonIGT group, death by cirrhosis had a relative risk of $21(9.1$ 
Table 2. Population characteristics at the first follow-up examination of the Paris Prospective Study; median (quartiles) or \%

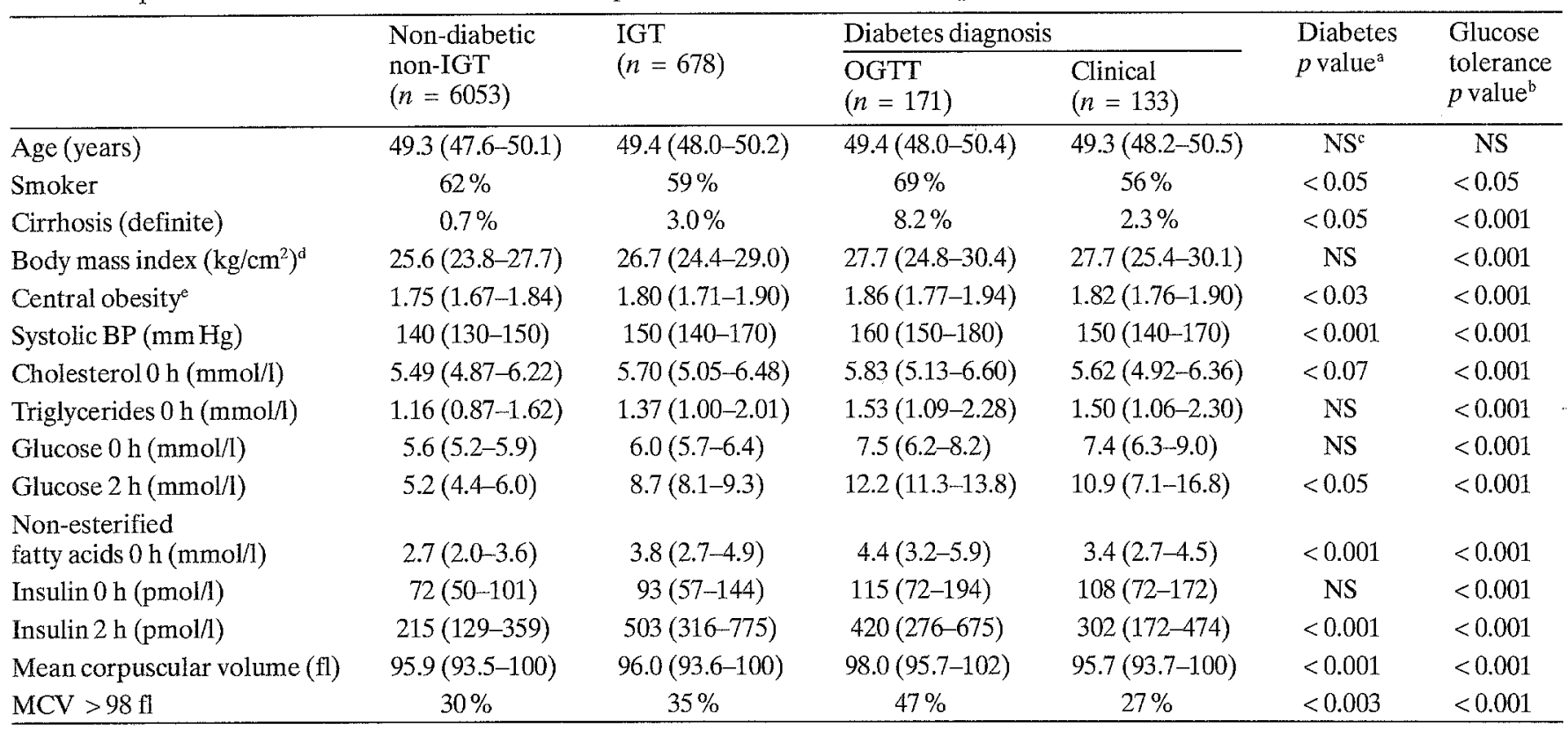

a Comparison of groups: 'OGTT diagnosed diabetes' and 'clinically diagnosed diabetes'; ' comparison of groups: non-diabetic/nonIGT, IGT and 'OGTT diagnosed diabetes'; "NS: $p>0.10$; ${ }^{\mathrm{d}}$ body mass index $=$ weight $(\mathrm{kg}) /(\text { height }(\mathrm{cm}))^{2} ;{ }^{\text {e }}$ central obesity $=($ iliac circumference) $/$ (thigh circumference). IGT $=$ impaired glucose tolerant; OGTT $=$ oral glucose tolerance test; $\mathrm{BP}=$ blood pressure

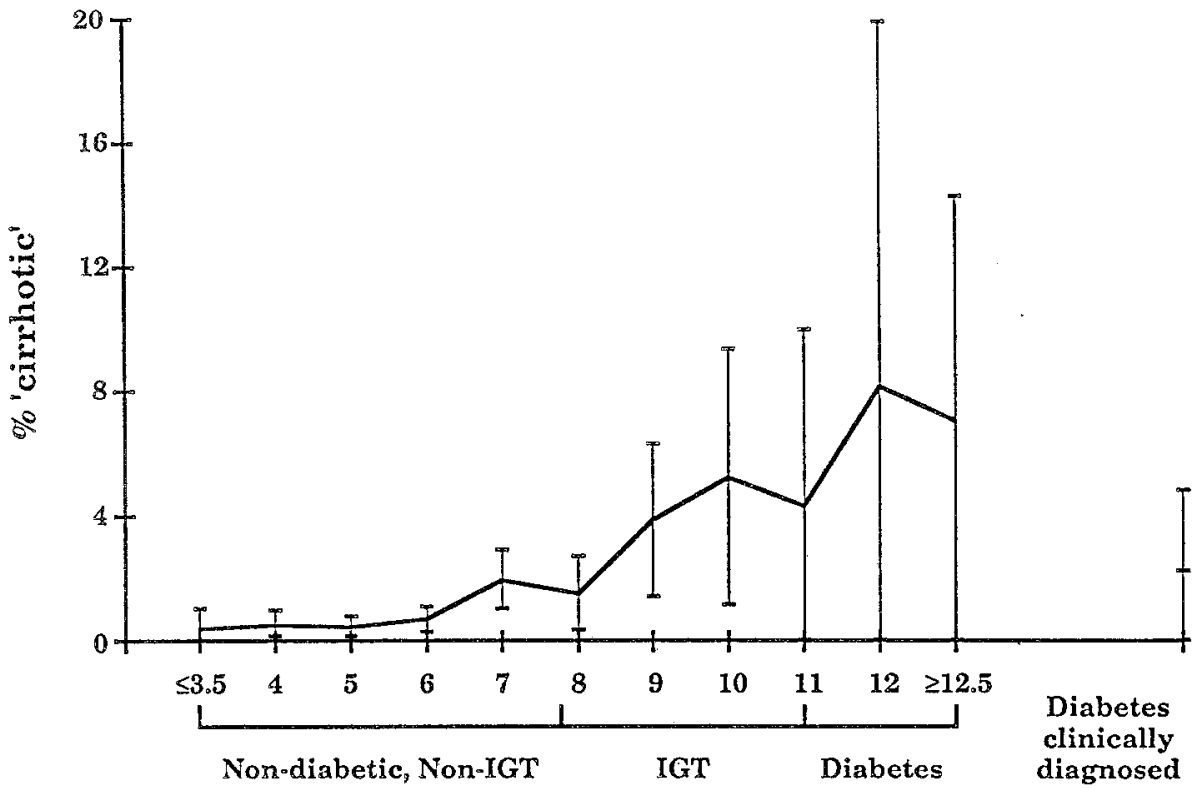

Fig. 1. Percentage of subjects with clinically diagnosed 'cirrhosis' (95\% confidence interval) by 2 -h glucose concentrations following an oral glucose tolerance test, and diabetic status. IGT = impaired glucose tolerance to 49) for the group with 'OGTT diagnosed diabetes'; the relative risk was 3.1 for the group with 'clinically diagnosed diabetes': (0.41 to 24). These relative risks differed at the $2 \%$ level. For death by cirrhosis or alcohol-related causes, the relative risks for these two groups were: 7.7 (4.5 to 13) and 3.2 (1.3 to 7.8 ), respectively. The relative risk in comparing these two groups was 2.5 (0.90 to 6.7), higher in the group with 'OGTT diagnosed diabetes'.

The IGT group had a relative risk of death by cirrhosis of 7.4 (3.4 to 16 ) in comparison to the normoglycaemic group; this risk is also elevated in comparison to those with 'clinically diagnosed diabetes'.

The risks of death by $\mathrm{CHD}$ in glucose intolerant subjects are well-known $[27,28]$. In this population, the relative risks for the groups with IGT, 'OGTT diagnosed diabetes' and 'clinically diagnosed diabetes' were of a similar order of magnitude being 1.6, 2.1 and 2.7, respectively; there was an increasing trend over the three glucose tolerance categories, non-diabetic/non-IGT, IGT, 'OGTT diagnosed diabetic' (Table 3). Using the wider grouping of death by cardio-cerebrovascular disease, relative risks for the groups with IGT, 'OGTT diagnosed diabetes' and 'clinically diagnosed diabetes' were $1.8,2.4$ and 2.7 , respectively. Along with this elevated risk of $\mathrm{CHD}$ and cardio-cerebrovascular mortality, factors associated with the insulin resistance 'Syndrome X' [29], (insulin, glucose, triglycerides, cholesterol concentrations and blood pressure) were elevated in the two diabetic groups in compari- 


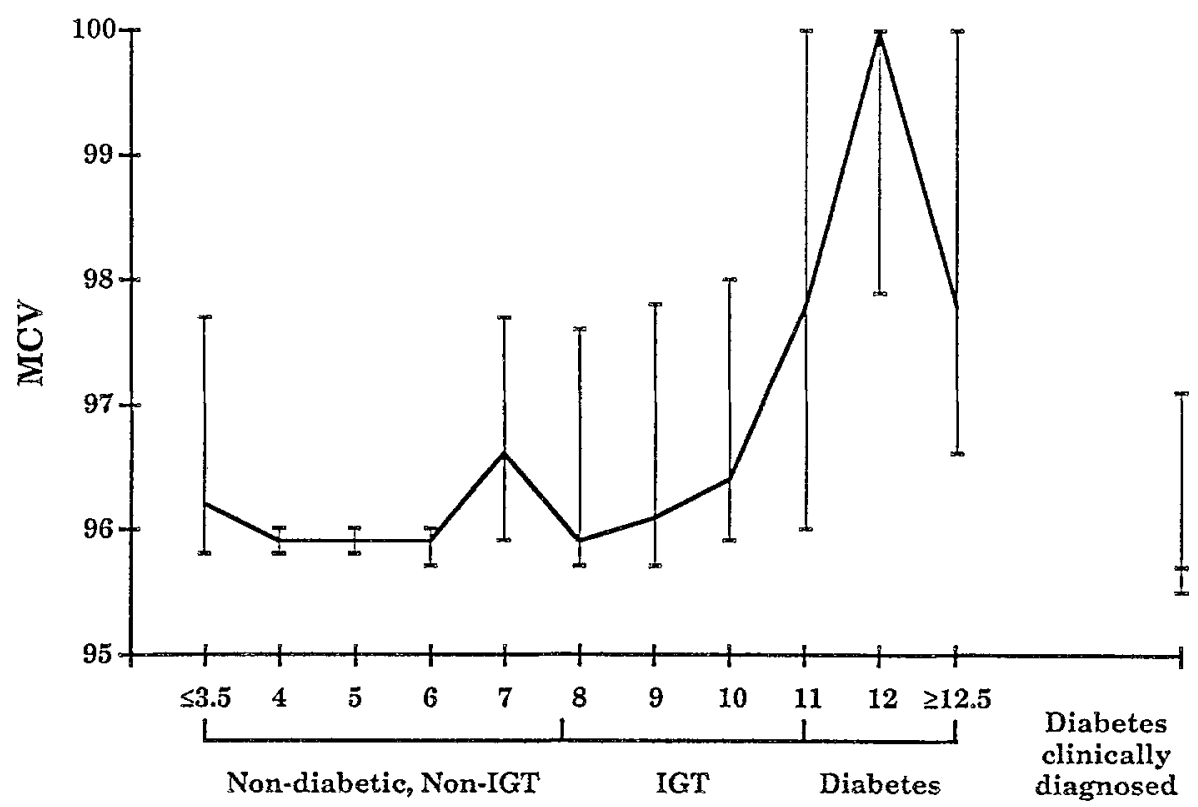

Fig. 2. Median values of mean corpuscular volume (MCV) (95\% confidence interval) by 2 -h glucose concentrations following an oral glucose tolerance test, and diabetic status. IGT = impaired glucose tolerance

Table 3. Number of deaths (D), relative risks (RR) (95\% confidence interval), after adjustment for age, by cause of death and by glucose tolerance group

\begin{tabular}{|c|c|c|c|c|c|c|c|c|c|}
\hline \multirow{2}{*}{ Cause of death } & \multirow{2}{*}{\multicolumn{2}{|c|}{$\begin{array}{l}\text { Non-diabetic } \\
\text { non-IGT } \\
(n=6053)\end{array}$}} & \multirow{2}{*}{\multicolumn{2}{|c|}{$\begin{array}{l}\text { IGT } \\
(n=678)\end{array}$}} & \multicolumn{4}{|c|}{ Diabetes diagnosis } & \multirow{2}{*}{$p$ value } \\
\hline & & & & & \multicolumn{2}{|c|}{$\begin{array}{l}\text { OGTT } \\
(n=171)\end{array}$} & \multicolumn{2}{|c|}{$\begin{array}{l}\text { Clinical } \\
(n=133)\end{array}$} & \\
\hline$\overline{\text { Cirrhosis }}$ & 15 & 1 & 12 & $7.4(3.4-16)$ & 9 & $21(9.1-49)$ & 1 & $3.1(0.41-24)$ & $<0.02$ \\
\hline Alcohol-related & 61 & 1 & 14 & $2.1(1.1-3.8)$ & 7 & $4.3(2.0-9.4)$ & 4 & $3.2(1.2-8.8)$ & $\mathrm{NS}^{\mathfrak{b}}$ \\
\hline Cirrhosis and alcohol-related & 76 & 1 & 26 & $3.1(2.0-4.9)$ & 16 & $7.7(4.5-13)$ & 5 & $3.2(1.3-7.8)$ & $<0.07$ \\
\hline Cardio-cerebrovascular & 210 & 1 & 40 & $1.8(1.2-2.5)$ & 14 & $2.4(1.4-4.2)$ & 12 & $2.7(1.5-4.9)$ & NS \\
\hline
\end{tabular}

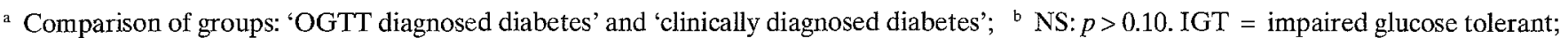
OGTT = oral glucose tolerance test

son with the non-diabetic/non-IGT group, and they showed a trend associated with increasing glucose intolerance (Table 2). The same pattern was seen for central obesity, a factor also associated with this syndrome [30].

\section{Discussion}

The group of men with 'OGTT diagnosed diabetes' in this French cohort, differed at the baseline examination from the group with 'clinically diagnosed diabetes' in markers of excessive alcohol consumption and in biological and clinical characteristics. They also had a high relative risk of death from alcohol-related causes, in particular cirrhosis. Further, there was a trend across the glucose tolerance categories, as defined by the OGTT. The hyperglycaemia in the 'OGTT diagnosed diabetic' subjects could have been due to an excessive consumption of alcohol in a certain percentage of these men screened as diabetic.

The first marker of excessive alcohol consumption, cirrhosis, had a prevalence of $8 \%$ in the "OGTT diagnosed diabetes' group, three times the pervalence in the 'clinically diagnosed diabetes' group. Cirrhosis was clinically evaluated and therefore 'soft data', however, as the examining physician had no knowledge of the glucose tolerance status of the subject there should be no related bias. In France, alcoholic cirrhosis is more common than all other liver diseases and thus physicians are better able to diagnose this condition clinically than in countries where the alcohol consumption is lower. The MCV, another marker of excessive alcohol consumption, is insensitive [16]. Smoking is known to increase the MCV at all levels of alcohol consumption [31]. After adjusting for the smoking habits of the 7035 subjects of this study, the difference in MCV between diabetic groups remained significant $(p<0.05)$. Death by cirrhosis could be called a third mar$\mathrm{ker}$, as it is an indicator of long-term alcohol consumption. Thus, it may be a more appropriate marker than one made only at entry to the study. All three markers of alcohol consumption were concordant, showing the same trend across the glucose tolerance categories, with 'clinically diagnosed diabetic' subjects being intermediate between the non-diabetic/non-IGT and the IGT groups. It would be expected that the real association between alcohol consumption and glucose tolerance would be even greater if the markers were more sensitive. 
However, in a sub-sample of 451 of these men in the Paris Prospective Study cohort, a dietary interview assessed their usual daily diet, including consumption of alcohol [32]. This group of subjects did not differ from the main population in clinical or biological characteristics, so their alcohol consumption is likely to be similar to that in the whole population. The median alcohol consumptions were: 43 ( $95 \%$ confidence interval: 41-48), 56 (32-66), 52 (27-64) and 47 (20-67) g/day for the non-diabetic/nonIGT, IGT, 'OGTT diagnosed diabetic' and the 'clinically diagnosed diabetic' subjects respectively. There was a wide range of values and the samples were particularly small for the two diabetic groups which had only 12 and 14 subjects. These medians suggest that the IGT and 'OGTT diagnosed diabetic' subjects had higher alcoholic consumption than the non-diabetic/non-IGT. All three markers are consistent with heavy alcohol consumption: (1) the six subjects with 'cirrhosis' in this sub-sample all drank more than $34 \mathrm{~g} /$ day, with four drinking more than $80 \mathrm{~g} /$ day; (2) the MCV was positively correlated, though weakly, with alcohol consumption $(r=0.18, p<0.001)$; (3) the one death by cirrhosis was a subject who drank $67 \mathrm{~g} /$ day.

Hypertension, dislipoproteinaemia, hyperglycaemia, hyperinsulinaemia and obesity, in particular central obesity are associated with diabetes and excessive alcohol consumption as well as with CHD [5, 9, 13, 29, 30, 33-35]. All of these markers of 'Syndrome $X$ ' were evident in the two groups of diabetic subjects. However, the 'clinically diagnosed diabetic' group was closer to normality than the group of diabetic patients newly diagnosed by the OGTT. It can be argued that subjects with "clinically diagnosed diabetes' were under medical care and had modified their consumption of alcohol and their diet; they may have also been treated by various drugs, for hypertension and hyperlipidaemia as well as for hyperglycaemia.

Of particular note, the elevated concentrations of insulin and glucose in the 'OGTT diagnosed diabetic' group were indicative of insulin resistance. This is consistent with the hypothesis that this group had, on average, a high consumption of alcohol: impaired insulin sensitivity has been observed in normal subjects after administration of alcohol [36] and hyperinsulinaemia is common in cirrhosis [37].

The most striking difference between diabetic subjects diagnosed by the two methods was in the differences in relative risks for death from cirrhosis and from alcohol-related causes; in contrast, there was little difference between the relative risks for death by CHD and by diseases related to the cardio-cerebrovascular system. The high risk of mortality by CHD could be the result of an exposure to the anomalies related to insulin resistance, whatever the initiating mechanism.

The protective effect of moderate alcohol consumption has been demonstrated in a number of populations and is described by a U-shaped curve relating alcohol consumption and CHD [38]. One rationale, which is still under discussion, is that alcohol raises the HDL cholesterol concentration [38-40]; HDL cholesterol was not measured in the Paris Prospective Study. In most of the studies which show this relationship, the consumption of alcohol was not as high as that observed in this study; the mean daily intake in the sub-sample of 451 men was $48 \mathrm{~g} /$ day, (median $43 \mathrm{~g} /$ day) with $66 \%$ consuming more than $34 \mathrm{~g} /$ day, $28 \%$ more than $64 \mathrm{~g} /$ day, $15 \%$ more than $80 \mathrm{~g} /$ day; this is similar to that observed in other French male populations [41]. In the Whitehall Study, for example, the heavy drinker category was $>34 \mathrm{~g} /$ day [38], in the New Zealand study only $8 \%$ consumed more than $64 \mathrm{~g} /$ day [42]. Chronic alcohol consumption was shown to be positively related to myocardial infarction, stroke and diabetes in the Gothenburg Population Cohort Study of men born between 1911-1940; alcoholism was diagnosed on admission to hospital [43]. In populations where the alcohol consumption is high, the U-shaped relationship between alcohol consumption and CHD may well become J-shaped [40].

The data from this study agree with the hypothesis of Björntorp [30,44] that alcohol may be one of the factors which leads to the accumulation of portal adipose tissue, as a consequence of a neuroendocrine aberration. The portal adipose tissue, which is measured in epidemiological studies by the waist-hip or iliac-thigh ratio, is a very sensitive system for the mobilisation of non-esterified fatty acids. Portal non-esterified fatty acids stimulate glucogenesis and the hepatic production and secretion of VLDL, as well as inhibiting the hepatic uptake of insulin. Thus, there is an increase in the values of factors defining 'Syndrome X', as well as peripheral non-esterified fatty acids, and an increase in CHD risk. In the group with 'OGTT diagnosed diabetes' there was evidence of a high alcohol consumption and a high risk of death by CHD.

In conclusion, in this French cohort of working men, subjects with 'OGTT diagnosed diabetes', as well as IGT subjects, were at a higher risk of death from alcohol-related causes than the 'clinically diagnosed diabetic' subjects. There was a similar (and not significantly different) CHD death rate in the IGT and in the two groups of diabetic subjects with the 'clinically diagnosed diabetic' subjects being at highest risk, followed by the 'OGTT diagnosed diabetic' and then the IGT subjects. Both groups of diabetic subjects presented elevated values for all of the insulin resistance factors of 'Syndrome X'. Prospective studies are required in subjects with an excessive consumption of alcohol to determine whether the hyperglycaemia represents 'true' Type 2 diabetes and similarly whether the hypertension is essential. Studies at the interface between epidemiology and clinical investigation [45] have become more and more necessary in order to understand the putative role of lifestyle factors (such as alcohol consumption) and the mechanisms which could lead to Type 2 diabetes and/or to cardiovascular disease.

Acknowledgements. The Paris Prospective Study is conducted by the "Groupe d'Etudes sur l'Epidémiologie de 1"Athérosclerose" (GREA) and is supported by INSERM (Units 21, 55, 169 and 258) and the Direction de l'Action Sociale, de l'Enfance et de la Santé de la Ville de Paris (DASES).

\section{References}

1. Bernard C (1877) Leçons sur le diabète et la glycogenèse animale. Ballière, Paris, pp 58-59 
2. Del Vecchio Blanco C, Gentile S, Marmo R, Carbone L, Coltorti M (1990) Alterations of glucose metabolism in chronic liver disease. Diab Res Clin Pract 8: 29-36

3. Umeki S, Hisamoto N, Hata Y (1989) Study on background factors associated with impaired glucose tolerance and/or diabetes mellitus. Acta Endocrinol (Copenh) 120: 729-734

4. Ohlson LO, Larsson B, Björntorp P et al. (1988) Risk factors for Type 2 (non-insulin-dependent) diabetes mellitus. Thirteen and one-half years of follow-up of the participants in a study of Swedish men born in 1913. Diabetologia 31:798-805

5. Lombrail P, Lang T, Degoulet P et al. (1988) Alcohol consumption and impaired glycoregulation results in a population of 6665 salaried employees. Eur J Epidemiol 4: 371-376

6. Megyesi C, Samols E, Marks V (1967) Glucose tolerance and diabetes in chronic liver disease. Lancet II: 1051-1056

7. Creutzfeldt W, Frerichs H, Sickinger K (1970) Liver diseases and diabetes mellitus. In: Popper H, Schaffner F (eds) Progress in liver disease, Vol 3. Grune and Stratton, New York, pp 371-407

8. Gérard MJ, Klatsky AL, Siegelaub AB, Friedman GD, Feldman R (1977) Serum glucose levels and alcohol-consumption habits in a large population. Diabetes 26: 780-785

9. Trell E, Kristenson H, Peterson et al. (1981) Two-hour glucose and insulin responses after a standardized oral glucose load in relation to serum gamma-glutamyl transferase and alcohol consumption. Acta Diabetol Lat 18: 311-317

10. Holbrook TL, Barrett-Connor E, Wingard DL (1991) A prospective population-based study of alcohol use and non-insulindependent diabetes mellitus. Am J Epidemiol 132: 902-909

11. Balkau B, Eschwège E, Ducimetière P, Richard J-L, Warnet J-M (1991) The high risk of death by alcohol related diseases in subjects diagnosed as diabetic and impaired glucose tolerant: the Paris Prospective Study after 15 years of follow-up. J Clin Epidemiol 44: 465-474

12. WHO Study Group (1985) Diabetes mellitus. WHO Tech Rep Series n $n^{\circ} 727$. WHO, Geneva

13. Ben G, Gnudi L, Maran A et al. (1991) Effects of chronic alcohol intake on carbohydrate and lipid metabolism in subjects with Type II (non-insulin-dependent) diabetes. Am J Med 90: 70-76

14. Rankin JG, Ashley MJ (1986) Alcohol-related health problems and their prevention. In: Last JM (ed) Public health and preventive medicine, 12th edn. Appleton-Century-Crofts, Norwalk, Conneticut, pp 1039-1073

15. Ducimetière P, Eschwège E, Papoz L, Richard JL, Claude JR, Rosselin GE (1980) Relationship of plasma insulin levels to the incidence of myocardial infarction and coronary heart diesease mortality in a middle-aged population. Diabetologia 19: 205-210

16. Chick J, Kreitman N, Plant M (1981) Mean cell volume and gamma-glutamyl-transpeptidase as markers of drinking in working men. Lancet I: $1249-1251$

17. Ducimetière P, Richard JL (1989) The relationship between subsets of anthropometric upper versus lower body measurements and coronary heart disease risk in middle-aged men. The Paris Prospective Study I. Int J Obes 13: 111-122

18. Cloarec-Blanchard L, Darne B, Ducimetière $P(1990)$ Is there an ideal distribution of adipose tissue? Lancet II: 1080

19. Etienne G, Papin JP, Renault M (1963) Une méthode simple de dosage du cholestérol par voie automatique. Ann Biol Clin 21: 851-859

20. Claude JR, Corre F (1968) Considérations pratiques sur le dosage semiautomatique des triglycérides sériques par fluorométrie (méthode de Kiessler et Lederer). Comparaison avec la méthode manuelle colorimétrique de Van Handel et Zilversmit. Ann Biol Clin 26: 451-454

21. Anonymous (1963) Méthodologie Technicon Auto-Analyser "N"2a, 2nd edn. Technicon Ltd

22. Antonis A (1965) Semi-automated method for the colorimetric determination of plasma free fatty acid. J Lipid Res 6: 307-312

23. Rosselin GE, Assan R, Yalow RS, Berson SA (1966) Separation of antibody bound and unbound peptide hormone labelled with iodine 131 by talcum powder and precipitated silica. Nature 212: $355-357$
24. Campbell MJ, Gardner MJ (1989) Calculating confidence intervals for some non-parametric analyses. In: Gardner MJ, Altman DG (eds) Statistics with confidence. Br Med J, pp 71-79

25. Armitage P, Berry G (1987) Statistical methods in medical research, 2nd edn. Blackwell, Oxford, pp 372-374

26. Cox DR (1971) Regression models and life-tables (with discussion). J R Statist Soc B 34: 187-220

27. Kessler II (1971) Mortality experience of diabetic patients. A twenty-six year follow-up study. Am J Med 51: 715-724

28. Panzram G (1987) Mortality and survival in Type 2 (non-insulin dependent) diabetes mellitus. Diabetologia 30: 123-131

29. Reaven GM (1988) Role of insulin resistance in human disease. Diabetes 37: 1595-1607

30. Björntorp P (1990) Obesity and diabetes. In: Alberti KGMM, Krall LP (eds) The diabetes annual/5. Elsevier, Amsterdam, pp 373-395

31. Eschwège $\mathrm{E}$, Papoz L, Lellouch J et al. (1978) Blood cells and alcohol consumption with special reference to smoking habits. $J$ Clin Pathol 31: 654-658

32. Cubeau J, Péquignot G (1980) La technique du questionnaire alimentaire quantitatif utilisé par la section nutrition de I'I.N.S.E. R. M. Rev Epidemiol Sante Publique 28: 367-372

33. Lang T, Degoulet P, Aime F, Devries C, Jacquinet-Salord M-C, Fouriaud C (1987) Relationship between alcohol consumption and hypertension prevalence in a French population. $\mathrm{J}$ Chron Dis 40: 713-720

34. Reaven PD, Barrett-Connor EL, Browner DK (1990) Abnormal glucose tolerance and hypertension. Diab Care 1:119-125

35. Durrington PN (1989) Hyperlipidaemia: diagnosis and management. Wright, London, pp 219-248

36. Avogaro A, Fontana P, Valerio A et al. (1987) Alcohol impairs insulin sensitivity in normal subjects. Diab Res 5:23-27

37. Petrides AS, DeFronzo RA (1989) Glucose metabolism in cirrhosis: a review with some perspectives for the future. Diab Metab Rev 5: 691-709

38. Marmot MG (1984) Alcohol and coronary heart disease. Int J Epidemiol 13: 160-167

39. Veenstra J, Ockhuizen T, Van De Pol H, Wedel M, Schaafsma G (1990) Effect of moderate dose of alcohol on blood lipids and lipoproteins postprandially and in the fasting state. Alcohol 25: 371-377

40. Keil U (1990) Alcohol consumption and its relation to hypertension and coronary heart disease. In: Leaf A, Weber PC (eds) Atherosclerosis reviews, Vol 21. Raven Press, New York, pp 4351

41. Péquignot G, Crosigani P, Terracini B et al. (1988) A comparative study of smoking, drinking and dietary habits in population samples in France, Italy, Spain and Switzerland. III. Consumption of alcohol. Rev Epidemiol Sante Publique 36: 177-185

42. Jackson R, Scragg R, Beaglehole R (1991) Alcohol consumption and risk of coronary heart disease. Br Med J 303: 211-216

43. Lindegard B, Langman MJS (1985) Marital state, alcohol consumption, and liability to myocardial infarction, stroke, diabetes mellitus, or hypertension in men from Gothenburg. Br Med J 291: $1529-1533$

44. Björntorp P (1990) "Portal" adipose tissue as a generator of risk factors for cardiovascular disease and diabetes. Arteriosclerosis 10: 493-496

45. Stern M (1988) Type II diabetes mellitus. Interface between clinical and epidemiological investigation: Diab Care 11:119-126

Received: 22 April 1991

and in revised form: 19 August 1991

\section{Dr. B. Balkau}

INSERM U21

16 ave Paul-Vaillant-Couturier

F-94807 Villejuif Cedex

France 